\title{
The sources of pain in osteoarthritis: a pathophysiological review
}

\author{
F. Salaffi ${ }^{1}$, A. Ciapetti ${ }^{1}$, M. Carotti ${ }^{2}$ \\ ${ }^{1}$ Rheumatology Department, Polytechnic University of the Marche, Ancona; \\ ${ }^{2}$ Radiology Department, Polytechnic University of the Marche, Ancona, Italy
}

\begin{abstract}
SUMMARY
The pain of osteoarthritis (OA) has multifaceted etiologies within and outside the joint. It is believed to be driven by both nociceptive and neuropathic mechanisms, as well as abnormal excitability in the pain pathways of the peripheral and central nervous system. Inflammation in the joint triggers a cascade of events that leads to peripheral sensitization, increased sensitivity of nociceptive primary afferent neurons, and hyperexcitability of the nociceptive neurons in the central nervous system. Pain receptors have been found in the synovium, ligaments, capsule, subchondral bone and surrounding tissues, with the exception of articular cartilage. The bone-related causes of pain in $\mathrm{OA}$ include subchondral microfractures, bone stretching with elevation of the periosteum due to osteophyte growth, bone remodeling and repair, bone marrow lesions, and bone angina caused by decreased blood flow and increased intra-osseous pressure. Central factors alter pain processing by setting the gain in such a way that, when a peripheral input is present, it is processed against a background of central factors that can enhance or diminish the experience of pain. As a complex phenomenon with a strong subjective component, pain can also be influenced by the nature of the underlying disease, personal predisposition (biological and psychological), and environmental and psychosocial factors.

This review examines the current literature regarding the sources and mechanisms of pain in OA.
\end{abstract}

Key words: Pain, Osteroarthritis, Risk factors.

Reumatismo, 2014; 66 (1): 57-71

\section{INTRODUCTION}

Osastant steoarthritis (OA) has been described as a condition characterized by wearand-tear related joint pain experienced on most days in any given month, for which no other cause is apparent (1). Joint pain is usually the main aspect of symptomatic OA that leads patients to seek medical attention.

Despite the exciting progress and growth in our understanding of the molecular and cellular mechanisms of OA, pain remains a challenging clinical entity to treat.

A large body of evidence suggests that OA is a heterogeneous condition that involves not only the articular cartilage, but also an adaptive response of the bone and the synovium to a variety of environmental, genetic and biomechanical stresses $(2,3)$.

It is also increasingly recognized that central pain sensitization and psychosocial factors are important determinants of pain severity in OA patients $(3,4)$. Recent studies of animal models provide support for the central sensitization of nociceptive pathways (5). In addition, the presence of hyperalgesia, abnormal pain sensitivity and referred pain have been widely documented (6-11).

This review examines the current literature regarding the sources and mechanisms of pain in OA.

\section{EPIDEMIOLOGY OF PAIN IN OA AND CLINICAL IMPLICATIONS}

$\mathrm{OA}$ is a major cause of musculoskeletal pain and the major cause of disability and handicap in Western industrialized countries (12).

It has been estimated that over 26 million people in the US were suffering from OA in 2005 (13). The prevalence of OA varies $\overline{\text { Corresponding author: }}$ Fausto Salaffi

Clinica Reumatologica Università Politecnica delle Marche c/o Ospedale "Carlo Urbani" Via dei Colli, 52 - 60035 Jesi (AN), Italy E-mail: fausto.salaffi@gmail.com 
greatly depending on the definition used, age, gender and geographical area. The overall prevalence of symptomatic OA in Italy has been estimated as being $8.95 \%$ (95\% CI 6.81-10.7) (14).

The most common site of OA is the knee, with a prevalence of $5.39 \%$ (95\% CI 3.41$7.99)$, followed by the hand $(1.95 \%, 95 \%$ CI $1.22-2.48)$ and hip $(1.61 \%, 95 \%$ CI $1.39-1.87)$ (14). OA of the knee has been identified as one of the main causes for physical disability in non-institutionalized elderly subjects (15). A number of studies have confirmed the severe multidimensional impact of OA on health-related quality of life (16-19) (Fig. 1). Older adults with OA of the lower extremities usually report a poorer physical and mental health status than those without (17).
$\mathrm{OA}$ is also a considerable community healthcare burden in terms of lost working days, early retirement and significantly increased welfare costs. The economic burden of OA is a result of both direct and indirect costs. Indirect costs include the loss of resources and productivity due to the disease.

Direct costs are related to medical expenditure.

Our previous multi-centric study showed that the total amount of direct medical costs (hospitalization, diagnosis and treatments) and indirect non-medical costs (transport, temporary caregivers and auxiliary devices) was more than $€ 553,000$; the annual cost per patient was $€ 2170$ (95\% CI $€ 1694-2647)$; and $57 \%$ of the overall costs were indirect costs (20).

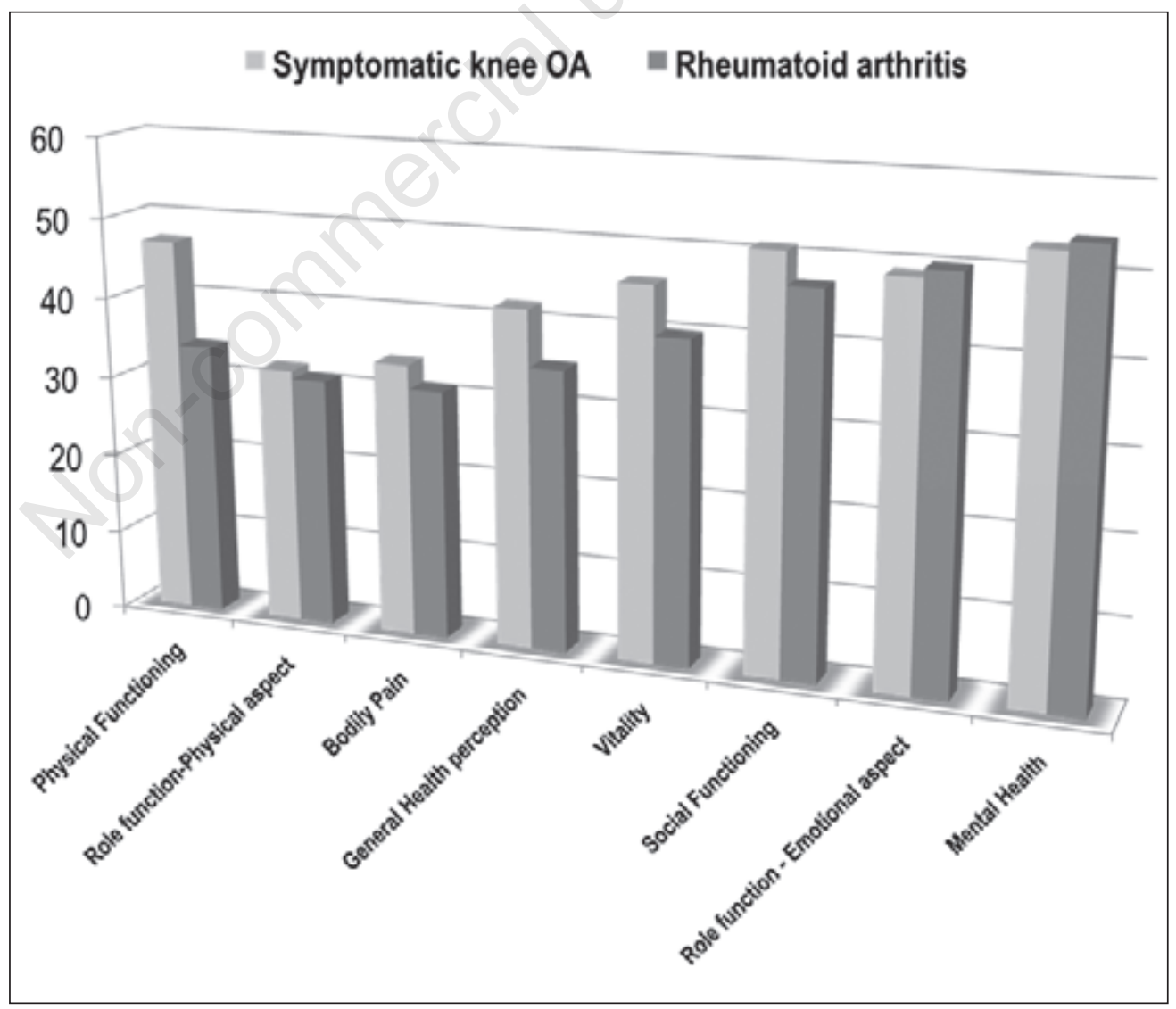

Figure 1 - Impact of health status on key areas (or domains) in symptomatic knee osteoarthritis ( $n=304$ patients) using the generic Medical Outcomes Study (MOS) 36-item Short-Form Health Survey (SF-36) questionnaire: comparison with rheumatoid arthritis ( $n=78$ patients). From Salaffi, 2003 (16). 


\section{BIOCHEMICAL PATHWAYS AND NEUROPEPTIDES IN OSTEOARTHRITIS}

It is believed that OA-related pain is the result of a complex interaction between local tissue damage, inflammation, and the peripheral and central nervous systems. Various studies have shown that it is driven by both nociceptive and neuropathic mechanisms $(21,22)$.

Nociceptive pain arises from the stimulation of peripheral nociceptors. The nociceptive signal is transmitted through the spinal cord to the brain via the ascending pathway and a number of neurotransmitters (e.g. glutamate, aspartate, substance $\mathrm{P}$, etc.) (23) (Fig. 2).

The inputs from the nociceptors are transmitted to the spinal cord through three types of fibers: myelinated A $\delta$ (group III) and unmyelinated $\mathrm{C}$ fibers (group IV), which innervate the synovial membrane, joint capsule, periarticular ligaments, menisci, adjacent periosteum and subchondral bone; and myelinated $A \beta$ fibers (group II), which innervate the synovial membrane, joint capsule, periarticular bursae, fat pad, ligaments, menisci and adjacent bony periosteum $(21,22)$.

$\mathrm{A} \beta$ fibers are usually activated by joint movement, whereas $\mathrm{A} \delta$ and $\mathrm{C}$ fibers are activated by noxious mechanical, chemical or thermal stimuli $(21,22)$.

Increasing or decreasing pain perceptions depend on the severity of the pain signal travelling through the descending pathways from the brain to the spinal cord (21, $22)$. Pain can also be generated by the activation of central nociceptive pathways (e.g. dysregulated neurotransmission or damage to the central nervous system) without involving peripheral nociceptors $(21,22)$. Although OA has been classified as a form of non-inflammatory arthritis, there is increasing evidence that inflammation oc-

\section{Supraspinal control of nociception}

\section{Ascending nociceptive pathways \\ Descending modulatory pathways}

- Substance P

- Glutamate and EAA

- Serotonin $\left(5 \mathrm{HT}_{2 \mathrm{a}, 3 \mathrm{a}}\right)$

- Neurotensin

- Bradykinin

- Cytokines and inflammation markers

- Nerve growth factor

- CGRP

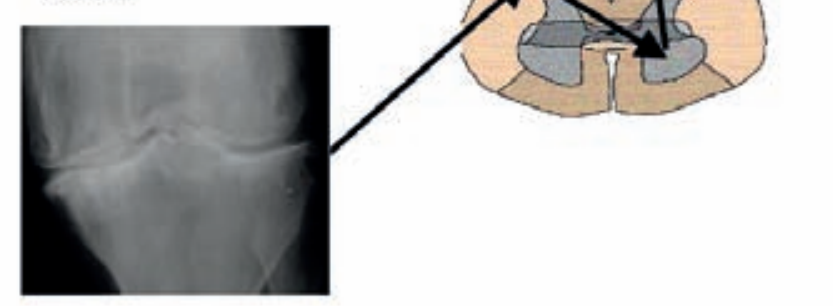

Inhibitors

- Noradrenaline

- Serotonin $\left(5 \mathrm{HT}_{10 . \mathrm{b}}\right)$

- Norepinefrine

- Opioids

- gaba

\section{Stimulators}

- Glutamate

- Aspartate

- Serotonin

Figure 2 - Neurological pain pathways in osteoarthritis. EAA, essential amino acids; CGRP, calcitonin gene-related peptide; GABA, $\gamma$-aminobutyric acid. 
curs as cytokines and metalloproteinases are released into the joint (24).

Recent studies have shown the relationship between pain and the inflammatory response in OA by identifying associations between psychophysical pain measures and pro-inflammatory cytokine levels $(21,22)$. The fact that OA patients are more sensitive to pressure stimuli at multiple sites suggests defects in central pain processing. In particular, pain and inflammation seem to play interactive roles: the inflammation contributes to enhancing pain sensitivity, and this may stimulate inflammatory responses $(21,22)$.

The inflammation markers released into the joint are involved in the matrix degradation that characterizes the cartilage degeneration that is typical of OA (24). The various cytokines (e.g. tumor necrosis factor) and mediators (pro-inflammatory interleukins, chemokines, nerve growth factor, leukotrienes, prostaglandins and matrix metalloproteinases) released in damaged tissue and the spinal cord induce a cascade of events that lead to peripheral sensitization, increased sensitivity of the nociceptive primary afferent neurons, and hyperexcitability of nociceptive neurons in the central nervous system (25).

The inflammatory mediators (e.g. bradykinin, substance P) released by chondrocytes as a consequence of cartilage damage induce hyperalgesia, and contribute to a self-propagating cycle in which more inflammatory mediators are released (21, 22). Macrophage-mediated inflammation may lead to angiogenesis by stimulating endothelial cells and fibroblasts to produce angiogenic factors (e.g. vascular endothelial growth factor) $(26,27)$. The hypoxia in inflamed tissues can stimulate angiogenesis and causing further inflammation (21, 26, 27).

Although OA-related pain is mainly considered to be a combination of nociceptive pain and local inflammatory processes, neuropathic mechanisms may also contribute to the pain experience. This is especially true when the local joint damage leads to the involvement of peripheral nerves and, consequently, neuropathic pain (28).

\section{JOINT DAMAGE/PAIN RELATIONSHIP IN OSTEOARTHRITIS}

Although a key pathological hallmark of $\mathrm{OA}$ is abnormal articular cartilage, cartilage is avascular and aneural, and so damaged cartilage cannot generate pain directly (29). However, subchondral bone, periosteum, periarticular ligaments, periarticular muscles, synovium and joint capsule are all richly innervated, and can therefore represent the nociceptive source of pain (Fig. 2).

Pain is reported by $10 \%$ of subjects with normal radiographs, and $40-79 \%$ of patients with the significant radiographic joint abnormalities typical of OA (30). A number of studies indicate that only half of the patients with radiographic OA feel pain, and that there is a weak correlation between pain severity and radiographic changes (31-34).

Even studies showing significant associations between changes in joint structure and symptoms have found that $51 \%$ of the subjects with knee pain for $>1$ year do not show any typical radiographic joint changes, and that up to $50 \%$ of patients with the radiographic changes of OA have no symptoms (35).

This suggests that the ability of radiography to distinguish painful and non-painful knees in the general population is limited, possibly because of a lack of sensitivity in detecting structural changes, differences in pain susceptibility, other personal determinants of OA symptoms, and obscure structure/pain relationships (36).

The bone changes in OA usually occur in two phases: a destructive phase (i.e. bone eburnation and/or deformation and cyst formation, especially at level of the joint exposed to pressure) and a productive phase (i.e. progressive remodeling, such as osteophytes). Following the disappearance of articular cartilage, subchondral bone undergoes various cellular and hypervascular processes, characterized by radiologicallydetectable bone eburnation due to the formation of new bone over existing trabecular bone. 
Cysts are an important sign of OA and are defined in various ways: synovial cysts, sub-chondral cysts, sub-articular pseudocysts, necrotic pseudocysts and vugs (Fig. $3)$.

The causes of pain in patients with OA include sub-chondral microfractures, bone stretching with lifting of the periosteum due to the formation of osteophytes, the remodeling and repair of lesions in the bone marrow, and bone angina due to reduced blood flow and increased intra-osseous pressure (37) (Fig. 4).

Magnetic resonance imaging (MRI) of the joints has enabled the three-dimensional measurement of structural features, including the direct assessment of cartilage damage that may cause pain, but cannot be visualized by conventional radiography, such as effusions, synovitis and subchondral bone edema (38) (Fig. 5). Javaid et al. (39) have recently confirmed previous reports of a correlation between knee pain, radiographically-assessed structural features of knee OA, and MRI findings (40). Nevertheless, no single MRI or radiographic finding performed well in discriminating painful and non-painful knees, which suggests that other factors can also substantially contribute to determining OA-related joint pain.

MRI has shown that significant anatomical changes such as bone marrow lesions (37, 41), sub-articular bone attrition (characterized by changes in subchondral bone height and contours) (42), synovitis, and effusion $(43,44)$ are related to knee pain (Fig. 5). Bone marrow lesions play a pivotal role in generating symptoms, and lead to disease progression (37), and it has recently been demonstrated that there is a relationship between bone marrow lesions and pain severity (41).

MRI allows the visualization of bone marrow edema, which appears as an area of hyperintense signal on T2-weighted fat-

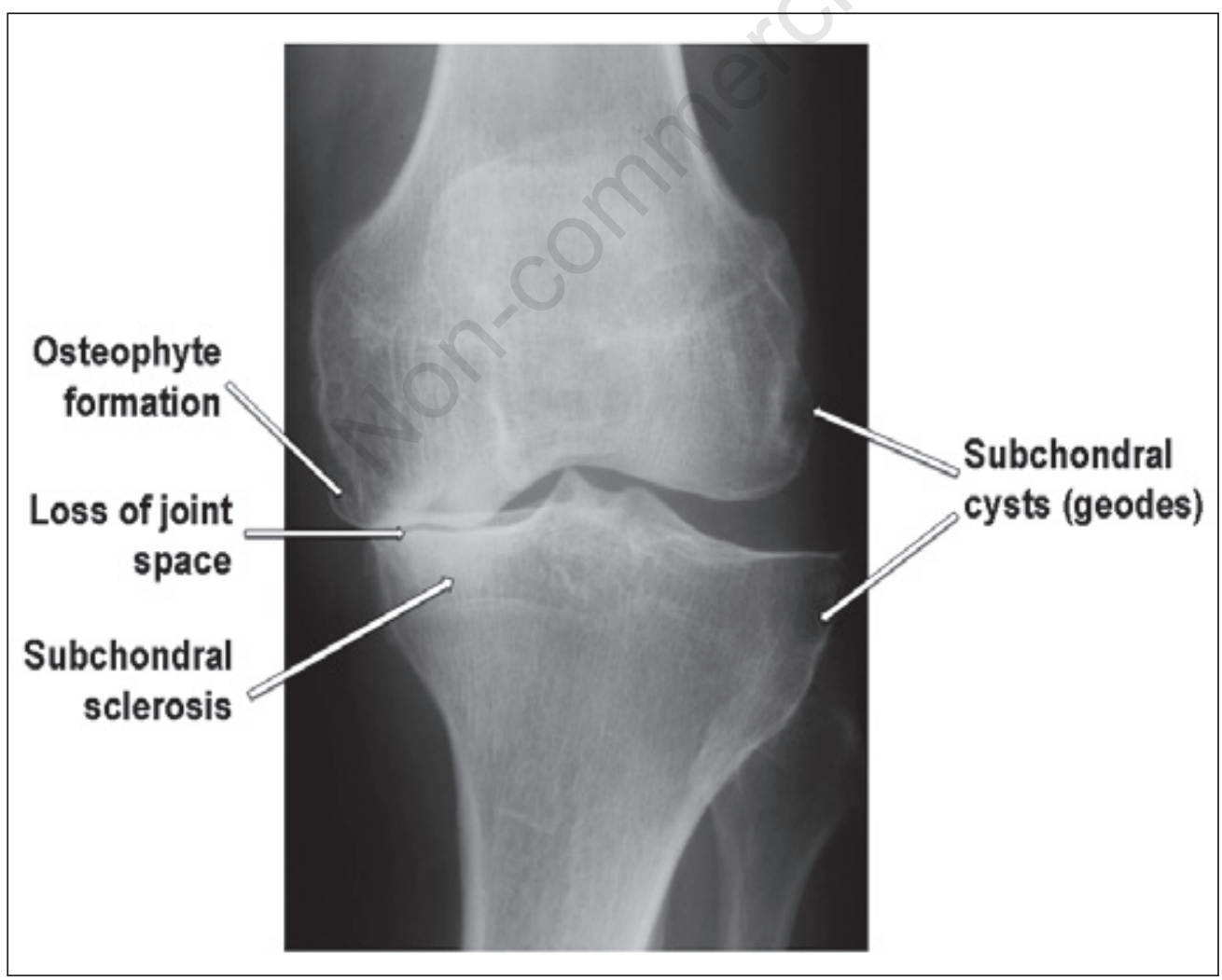

Figure 3 - Anteroposterior radiograph of the knee of a patient with osteoarthritis. Note the varus malalignment (resulting in bow-legs) due to loss of cartilage and joint space in the medial compartment, subchondral cysts and osteophyte formation. 
suppressed scans (Fig. 5) (37). A histopathological study of patients with OA (45) has shown that the pattern of bone marrow edema correlates with bone infarction or necrosis, bone fibrosis, bone marrow necrosis, and abnormal trabecular bone. Another study (46) has found that fibrovascular tissue also correlates with bone marrow edema. A number of studies of knee OA have shown a close correlation between bone marrow edema and pain $(37,47-49)$. For example, Felson et al. (37) studied 401 patients and found a higher incidence of bone edema ( $78 \%$ of those with knee pain against $30 \%$ of asymptomatic subjects) and MRI-detected anatomical joint damage. However, other studies have not documented any relationship (50-52).

Other bone-related causes of pain include periostitis associated with osteophyte formation (53), sub-chondral microfractures (54) and bone angina due to decreasing blood flow and increasing intra-osseous pressure (55). The pathophysiology of intra-osseous hypertension remains unclear, although phlebographic studies of OA patients have found impaired vascular clear- ance from bone and increased intra-osseous pressure in the bone marrow near the painful joint (55-58). However, the cause of the resulting pain is still unknown, although increased trabecular bone pressure, ischemia, and inflammation are all possible stimuli.

The synovial reaction in OA includes synovial hyperplasia, fibrosis, thickening of the synovial capsule, activated synoviocytes and, in some cases, lymphocytic infiltration (59). However, the presence of inflammatory cells (e.g. macrophages and lymphocytes) does not seem to be as important in OA as in rheumatoid arthritis (60). Synovitis is frequently present in OA, and studies have shown a correlation between synovitis and pain $(42,44)$, even in patients without any radiographic evidence of OA (61). Moreover, synovitis can predict anatomical changes as a recent MRI study of patients with knee OA (62) documented a significant correlation between synovitis and cartilage damage.

The site of infiltration of the synovium by inflammatory markers is clearly important because the intra-articular fat pad is one

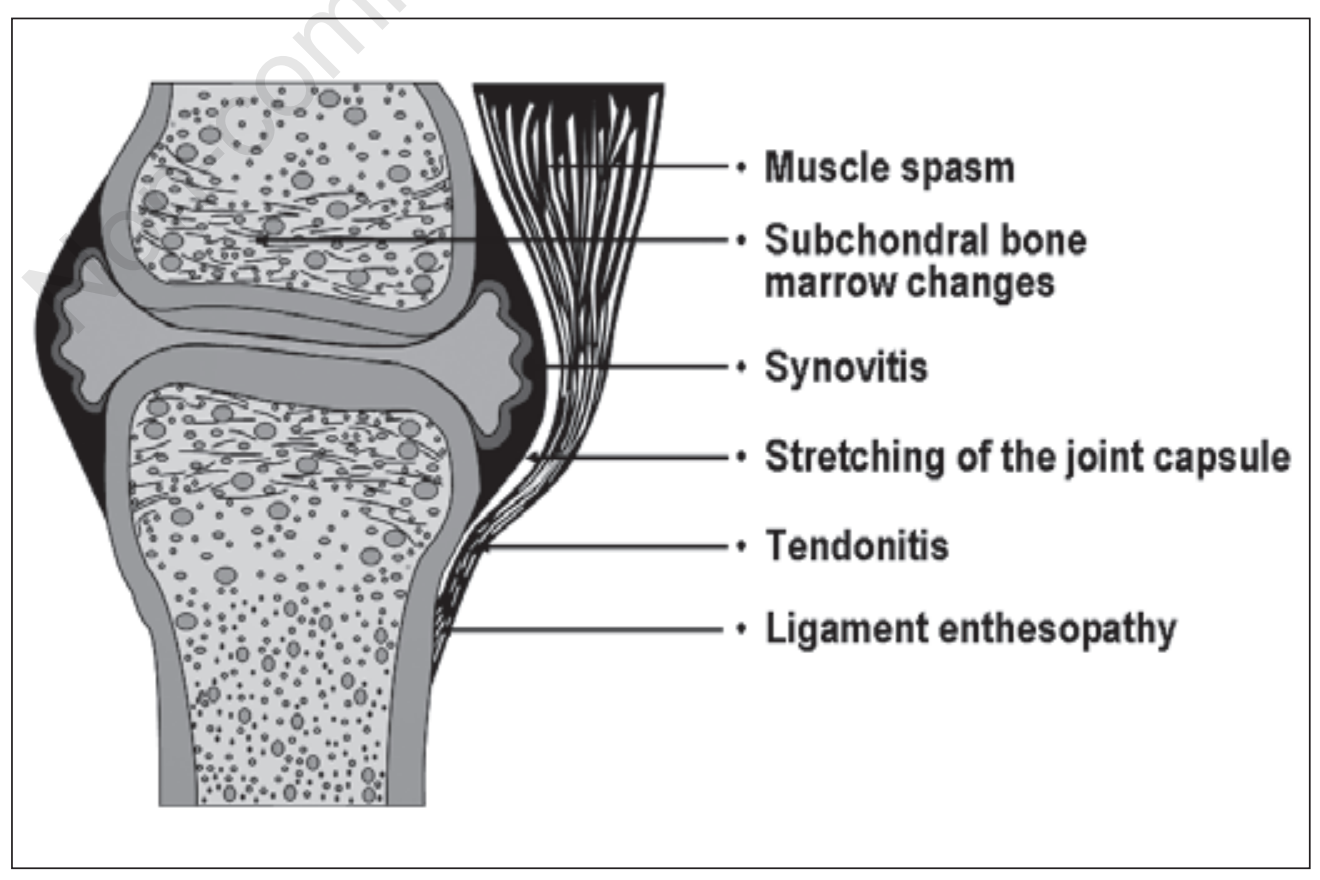

Figure 4 - Pathophysiological mechanisms and sites of pain in osteoarthritis. The different anatomical sites involved in the degenerative process contribute to the genesis and maintenance of pain. 
of the most densely innervated structures of the joint, and can act as a rich source of inflammatory activity. The synovial causes of pain include irritation of sensory nerve endings within the synovium due to osteophytes, and synovial inflammation, which is at least partially due to the release of prostaglandins, leukotrienes, proteinases, neuropeptides and cytokines (63). It has been shown that synovial thickening around the infra-patellar fat pad, which can be visualized by means of non-contrast MRI, histologically corresponds to chronic synovitis (64).

A different source of joint pain in OA may be the involvement of nerves. Following joint injury and ligamentous rupture, the nerves responsible for re-innervating the healing soft tissue release an over-abundance of algesic chemicals, such as substance $\mathrm{P}$ and calcitonin gene-related peptide (CGRP).

One recent hypothesis suggests a correlation between neoangiogenesis and OArelated pain (65). The articular cartilage is separated from the subchondral bone by a layer of calcified cartilage that undergoes severe alterations in its cellular composition and structure during the course of OA. This process is characterized by blood vessels penetrating the calcified cartilage from subchondral bone, and the presence of perivascular sensory nerve structures may partially explain the painful component related to neoangiogenesis.

Non-myelinated nerve fibers can amplify the inflammatory response by releasing vasoactive substances (neuropeptides) such as substance P and CRGP. Additionally, hypoxia in the inflamed tissue is a potent stimulator of angiogenesis, and causes further inflammation and pain due to the formation of new vessels and their innervation. Endochondral ossification and the formation of osteophytes occur at the osteochondral junction in response to angiogenesis, thus exacerbating the inflammation and associated pain.

The bone-related causes of pain in OA include sub-chondral microfractures, bone stretching with elevation of the periosteum due to osteophyte growth, bone remodeling and repair, bone marrow lesions and bone angina caused by decreased blood flow and

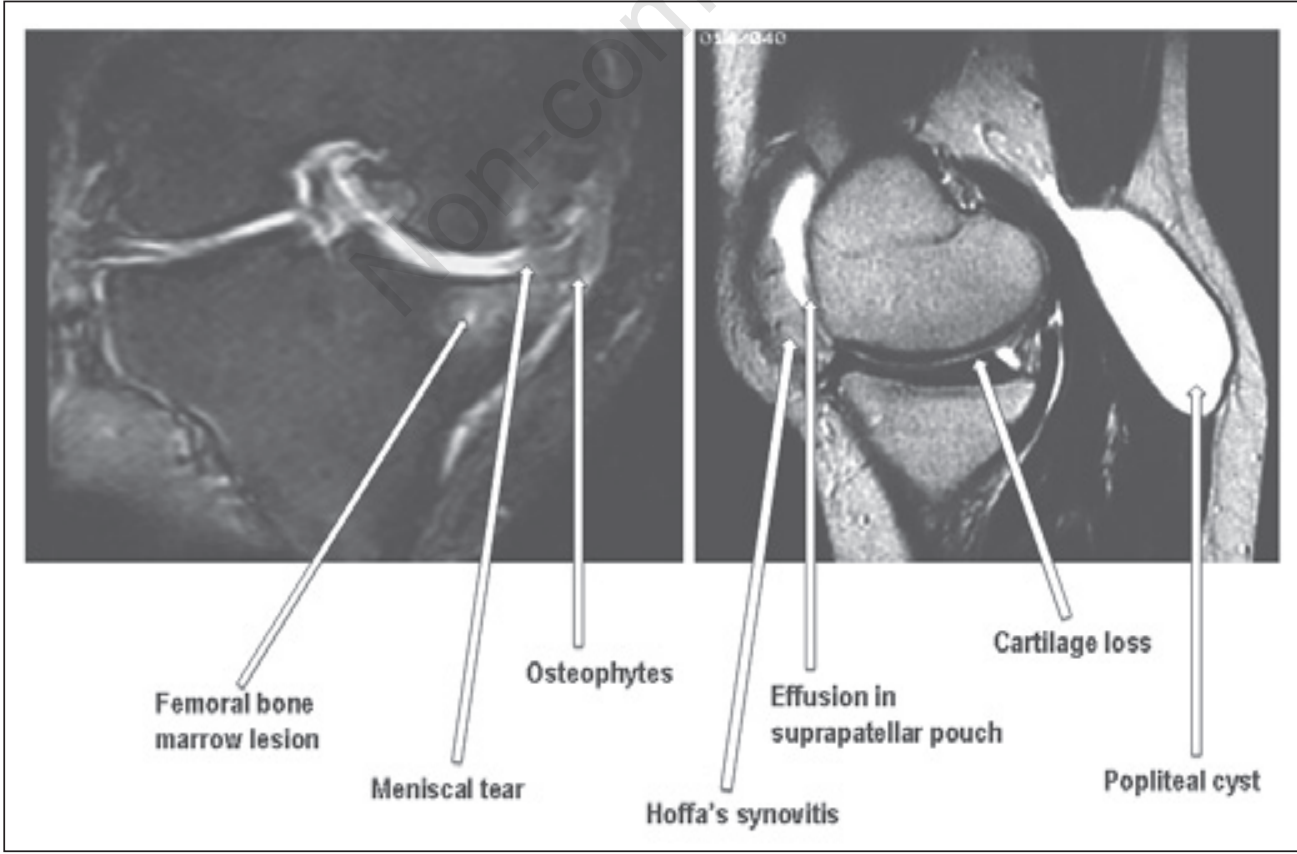

Figure 5 - Magnetic resonance imaging of a patient with knee osteoarthritis showing a bone marrow lesion, meniscal tear, osteophytes, a synovitis-like signal in Hoffa's fat pad, effusion in the supra-patellar pouch, cartilage loss and a popliteal cyst. 
high intra-osseous pressure $(26,37)$. MRIdetected bone marrow lesions (also called bone edema) seem to reflect bone infarction and are associated with higher levels of OA pain and a greater likelihood of disease progression (37).

\section{CENTRAL SENSITIZATION OF PAIN IN OSTEOARTHRITIS}

Central sensitization in OA can be defined as a state in which neurons activated and sensitized by nociceptive stimuli become hyper-responsive to further stimuli (66). It is believed that peripheral sensitization plays an important role in the development and maintenance of central sensitization (4). A persistent, intense or repeated input from peripheral nociceptors can modulate the activity of spinal cord pain-transmitting neurons, decrease the activation of pain thresholds and increase synaptic excitability (4).

Central sensitization may lead to pain threshold changes and the generation of pain hypersensitivity. A number of studies of OA have shown that an excess nociceptive ascending input and deficient inhibitory input may lead to the development and maintenance of central pain sensitization $(66,67)$. In addition, the sensitization of bone marrow neurons and peripheral nociceptive stimuli can be determined by changes in the regulatory tone (lack of inhibition or stimulation) that is normally guaranteed by the descending pathways of supraspinal centers.

Possible changes in the algogenic threshold may therefore be the result of supraspinal center stimulation or a reduction in inhibitory activity (4).

It has been clearly shown that patients with OA (and those with other chronic rheumatic diseases) have lower overall pain thresholds and less descending analgesic activity than healthy subjects $(24,68)$. Furthermore, the role of centralized pain in OA has recently been confirmed by randomized controlled studies demonstrating the efficacy of medications such as serotonin or norepinephrine (e.g. duloxetine and tricyclic antidepressants) in altering pain neurotransmitters centrally $(69,70)$.

\section{CONSTITUTIONAL AND BIO-PSYCHOSOCIAL FACTORS OF OSTEOARTHRITIS PAIN}

The sources of pain in OA and other regional pain syndromes are still unclear. It is mainly considered to be the result of a bio-psychosocial network in which each of many biological, psychological and social factors plays a significant role $(2,3,71$ 73). Pain is considered a better predictor of disability than the degree of radiographic damage (74).

Pain receptors have been found in the synovium, ligaments, capsule, subchondral bone and surrounding tissues with the exception of articular cartilage (Fig. 3 and 4). The perception of pain is regulated at the spinal and cortical level (Fig. 2) and is often influenced by psychosocial conditions. Factors underlying OA such as psychosocial factors, mood and coping can influence pain severity, and should be considered in the light of age, gender, anatomical site, body mass index (BMI), comorbidities, educational level, and other psychological factors $(75,76)$.

\section{Age}

Although elderly subjects are vulnerable to OA pain, previous studies have not shown any significant difference between subgroups of $\mathrm{OA}$ patients stratified by age ( $<65$ vs $>65$ years) $(18,77)$, and other researchers have failed to find an association between age and physical function or the presence or severity of pain in OA (78-80).

\section{Gender}

Some community studies $(80,81)$, but not others (79), have found that women tend to report knee pain more frequently than men, and our own findings confirm earlier observations $(80,81)$ that females usually report more severe knee pain $(77,82,83)$. Some investigators have suggested that genderrelated differences may be due to the fact 
that women are more sensitive to pain (84) and therefore report pain more frequently (85). Other studies have also shown gender differences in terms of coping with pain (86), which may be indirectly related to factors such as physical activities, marital status or age. Furthermore, it has been found that there are statistically significant differences in pain ratings by gender (17).

\section{Localization of osteoarthritis}

Allen et al. (87) observed differences in daily pain ratings depending on the site of the affected joint: hand OA was associated with less pain range and severity, whereas the pain ratings of patients with hip and knee OA were relatively similar. Hand OA is usually considered to be less painful than hip or knee OA, but no differences in within-day pain ranges have been reported. The smaller pain range in the case of hand OA may be related to the absence of the weight-bearing loads sustained by hip and knee throughout the day. In a study by Cimmino et al. (88) and one of our previous studies (17), hip OA was rated as being more painful than knee OA, but patients with generalized OA report high levels of overall pain $(83,89,90)$.

\section{Overweight}

Overweight is more common in knee OA patients than in the general population (91). Although BMI is clearly a strong risk factor for anatomical damage, it does not closely correlate with pain $(81,92,93)$. Nevertheless, population-based studies have shown an association between excess weight and knee OA: in the Amsterdam osteoarthritis cohort, BMI was independently associated with knee pain and activity limitations in patients with knee OA (94), and Paradowski et al. (95) showed that overweight may predispose for variations in pain and function over two years.

Various mechanisms have been suggested to explain the associations between BMI, knee pain and activity limitations in patients with knee OA, including increased mechanical stress. Overweight increases the load on the knees during weight-bearing activities, which may lead to pain and functional limitations (96). However, no statistically significant associations were found between BMI and functional disability assessed using the Western Ontario and McMaster Universities (WOMAC) Osteoarthritis Index questionnaire (77).

\section{Comorbidities}

Evidence of clinical associations between the radiographic features of $\mathrm{OA}$ and comorbidities have been recently provided by Addimanda et al. (97), who noted significant associations between hand $\mathrm{OA}$ and hypercholesterolemia (odds ratio: 2.10) and autoimmune thyroiditis (odds ratio: 4.85). Massengale et al. (98) have also reported an association between coronary heart disease and the intensity of chronic pain in hand OA (98).

The pain and functional limitation of the knee often reported by elderly subjects does not seem to be correlated to the pathological process in the knee, but to the involvement of hip or spine, and can therefore be a confounding element when interpreting the origin of pain $(99,100)$.

Data from the National Health Interview Survey Supplement on Aging (101-103), the Longitudinal Supplement on Aging (101-103), the Ontario Health Survey (104), and the Women's Health and Aging Study (105) have demonstrated the role of comorbidities in the relationship between OA and disability, and we have reported a significant relationship between pain and the number of comorbidities in patients with symptomatic hip and knee OA (17, 77).

\section{Educational level}

It has been reported that a shorter formal education is a risk factor for knee pain and physical function in the community, and we have found that educational level is related to mobility, arm function, pain and working ability as measured by Arthritis Impact Measurement Scales (AIMS2) (83), WOMAC subscores (77), and the SF36 MCS scale score (17).

This suggests that formal education should be included among the dependent variables in clinical trials involving patients with 
knee and hip OA (106). The mechanism by which education influences pain severity or psychological processes is unclear, but it may be related to enhanced self-efficacy and a sense of control over pain that allow patients to take advantage of a greater number of pain-reducing modalities. Like others $(31,78,107,108)$, we have found (18) that radiographic severity as measured by the $\mathrm{K} / \mathrm{L}$ grade (17) is not associated with pain severity. There are frequent discordances between radiographic findings and reports of joint pain in OA. In a survey of people aged 40-79 years in Nottingham, UK, $37.7 \%$ of those with knee pain had no radiographic evidence of OA compared with $58.7 \%$ of those without knee pain (109). In a further study of women aged 45-64 years, nearly 50\% of the patients with radiographic knee OA did not report any pain (110).

\section{Psychological factors}

It has long been recognized that pain is a complex sensory and emotional experience (111), and therefore requires consideration of the environmental processes and psychological and social factors that mediate an individual's response if it is to be fully understood (112). A number of studies support the importance of psychological factors in understanding OA pain (113), and it has been reported that pessimism is associated with poor physical outcomes (114). Observational studies also suggest that a negative mood is often related to polyarticular disease and a greater degree of physical disability (115), and qualitative studies have shown that patients with OA declare less satisfaction with their lives, and that depression and anxiety are their main psychological problems (116). The activities most frequently involved in the degenerative process are leisure activities (e.g. trips), social activities, personal relationships, work, and heavy housework (117). Although the majority of OA patients show a good capacity for symptom selfmanagement (118), some with long-standing OA perceive the disease as a threat to their identity and sense a lack of power to change their situation (119). As in the case of other chronic conditions, strategies for coping have proved to be crucial in managing the pain and disability associated with knee OA (120).

\section{REFERENCES}

1. WHO Scientific Group on the Burden of Musculoskeletal Conditions at the Start of the New Millennium. The burden of musculoskeletal conditions at the start of the new millennium. World Health Organ Tech Rep Ser. 2003; 919: i-x, 1-218.

2. Hunter DJ, McDougall JJ, Keefe FJ. The symptoms of osteoarthritis and the genesis of pain. Med Clin North Am. 2009; 93: 83100.

3. Dieppe PA, Lohmander LS. Pathogenesis and management of pain in osteoarthritis. Lancet. 2005; 365: 965-73.

4. Mease PJ, Hanna S, Frakes EP, Altman RD. Pain mechanisms in osteoarthritis: understanding the role of central pain and current approaches to its treatment. J Rheumatol. 2011; 38: 1546-5.

5. Sagar DR, Staniaszek LE, Okine BN, Woodhams S, Norris LM, Pearson RG, et al. Tonic modulation of spinal hyperexcitability by the endocannabinoid receptor system in a rat model of osteoarthritis pain. Arthritis Rheum. 2010; 62: 3666-76.

6. Farrell M, Gibson S, McMeeken J, Helme R. Pain and hyperalgesia in osteoarthritis of the hands. J Rheumatol. 2000; 27: 441-7.

7. Hendiani JA, Westlund KN, Lawand N, Goel $\mathrm{N}$, Lisse J, McNearney T. Mechanical sensation and pain thresholds in patients with chronic arthropathies. J Pain. 2003; 4: 203-11.

8. Kosek E, Ordeberg G. Abnormalities of somatosensory perception in patients with painful osteoarthritis normalize following successful treatment. Eur J Pain. 2000; 4: 229-38.

9. Ordeberg G. Characterization of joint pain in human OA. Novartis Found Symp. 2004; 260: 105-15.

10. Bajaj P, Bajaj P, Graven-Nielsen T, ArendtNielsen L. Osteoarthritis and its association with muscle hyperalgesia: an experimental controlled study. Pain. 2001; 93: 107-14.

11. Street J, Lenehan B, Flavin R, Beale E, Murray $P$. Do pain referral patterns determine patient outcome after total hip arthroplasty? Acta Orthop Belg. 2005; 71: 540-7.

12. Litwic A, Edwards MH, Dennison EM, Cooper C. Epidemiology and burden of osteoarthritis. Br Med Bull. 2013; 105: 185-99.

13. Lawrence RC, Felson DT, Helmick CG, Arnold LM, Choi H, Deyo RA, et al. Estimates of the prevalence of arthritis and other rheu- 
matic conditions in the United States. Part II. Arthritis Rheum. 2008; 58: 26-35.

14. Salaffi F, De Angelis R, Grassi W, MArche Pain Prevalence; INvestigation Group (MAPPING) study. Prevalence of musculoskeletal conditions in an Italian population sample: results of a regional communitybased study. I. The MAPPING study. Clin Exp Rheumatol. 2005; 23: 819-28.

15. Guccione AA, Felson DT, Anderson JJ, Anthony JM, Zhang Y, Wilson PW, et al. The effects of specific medical conditions on the functional limitations of elders in the Framingham Study. Am J Public Health. 1994; 84: 351-8.

16. Salaffi F. Pain in osteoarthritis: assessment and impact on the disability. Reumatismo. 2003; 55: 19-37.

17. Salaffi F, Carotti M, Stancati A, Grassi W. Health-related quality of life in older adults with symptomatic hip and knee osteoarthritis: a comparison with matched healthy controls. Aging Clin Exp Res. 2005; 17: 255-63.

18. Yildiz N, Topuz O, Gungen GO, Deniz S, Alkan $\mathrm{H}$, Ardic F. Health-related quality of life (Nottingham Health Profile) in knee osteoarthritis: correlation with clinical variables and self-reported disability. Rheumatol Int. 2010; 30: 1595-600.

19. Cavalieri F, Salaffi F, Ferraccioli GF. Relationship between physical impairment, psychological variables and pain in rheumatoid disability. An analysis of their relative impact. Clin Exp Rheumatol. 1991; 9: 47-50.

20. Leardini G, Salaffi F, Caporali R, Canesi B, Rovati L, Montanelli R, Italian Group for Study of the costs of arthritis. Direct and indirect costs of osteoarthritis of the knee. Clin Exp Rheumatol. 2001; 22: 699-706.

21. Mease PJ, Hanna S, Frakes EP, Altman RD. Pain mechanisms in osteoarthritis: understanding the role of central pain and current approaches to its treatment. J Rheumatol. 2011; 38; 1546-51.

22. Dray A, Read SJ. Arthritis and pain. Future targets to control osteoarthritis pain. Arthritis Res Ther. 2007; 9: 212.

23. Schaible HG, Schmelz M, Tegeder I. Pathophysiology and treatment of pain in joint disease. Adv Drug Deliv Rev. 2006; 58: 323-42.

24. Lee YC, Lu B, Bathon JM, Haythornthwaite JA, Smith MT, Page GG, et al. Pain sensitivity and pain reactivity in osteoarthritis. Arth Care Res. 2011; 63: 320-7.

25. Schaible HG, Ebersberger A, von Banchet GS. Mechanisms of pain in arthritis. Ann N Y Acad Sci. 2002; 966: 343-54.

26. Bonnet CS, Walsh DA. Osteoarthritis, angiogenesis and inflammation. Rheumatology. 2005; 44: 7-16.

27. Benedetti S, Canino C, Tonti G, Medda V, Calcaterra P, Nappi G, et al. Biomarkers of oxidation, inflammation and cartilage degradation in osteoarthritis patients undergoing sulfur-based spa therapies. Clin Biochem. 2010; 43: 973-8.

28. Schaible HG, Richter F, Ebersberger A, Boettger MK, Vanegas H, Natura G, et al. Joint pain. Exp Brain Res. 2009; 196: 153-62.

29. Felson DT. The epidemiology of knee osteoarthritis: results from the Framingham Osteoarthritis Study. Semin Arthritis Rheum. 1990; 3: 42-50.

30. Creamer P, Lethbridge-Cejku M, Hochberg MC. Where does it hurt? Pain localization in osteoarthritis of the knee. Osteoarthritis Cartilage. 1998; 6: 318-23.

31. Van Saase JLCM, van Romunde LKJ, Cats A, Vandenbroucke JP, Valkenburg HA. Epidemiology of osteoarthritis: Zoetermeer survey. Comparison of radiological osteoarthritis in a Dutch population with that in 10 other populations. Ann Rheum Dis. 1989; 48: 271-80.

32. Finan PH, Buenaver LF, Bounds SC, Hussain S, Park RJ, Haque UJ, et al. Discordance between pain and radiographic severity in knee osteoarthritis: findings from quantitative sensory testing of central sensitization. Arthritis Rheum. 2013; 65: 363-72.

33. Bedson J, Croft PR. The discordance between clinical and radiographic knee osteoarthritis: a systematic search and summary of the literature. BMC Musculoskelet Disord. 2008; 9: 116.

34. Dieppe PA. Relationship between symptoms and structural change in osteoarthritis: what are the important targets for therapy? J Rheumatol 2005; 32: 1147-9.

35. Duncan R, Peat G, Thomas E, Hay E, McCall I, Croft P. Symptoms and radiographic osteoarthritis: not as discordant as they are made out to be? Ann Rheum Dis. 2007; 66: 86-91.

36. Gwilym SE, Keltner JR, Warnaby CE, Carr AJ, Chizh B, Chessell I, et al. Psychophysical and functional imaging evidence supporting the presence of central sensitization in a cohort of osteoarthritis patients. Arthritis Rheum. 2009; 61: 1226-34.

37. Felson DT, Chaisson CE, Hill CL, Totterman SM, Gale ME, Skinner KM, et al. The association of bone marrow lesions with pain in knee osteoarthritis. Ann Intern Med. 2001; 134: 541-9.

38. Conaghan PG, Felson D, Gold G, Lohmander S, Totterman S, Altman R. MRI and non-cartilaginous structures in knee osteoarthritis. Osteoarthritis Cartilage. 2006; 14: A87-94.

39. Javaid MK, Kiran A, Guermazi A, Kwoh CK, Zaim S, Carbone L, et al. Individual magnetic resonance imaging and radiographic features of knee osteoarthritis in 
subjects with unilateral knee pain. Arthritis Rheum. 2012; 64: 3246-55.

40. Neogi T, Felson D, Niu J, Nevitt M, Lewis $\mathrm{CE}$, Aliabadi P, et al. Association between radiographic features of knee osteoarthritis and pain: results from two cohort studies. BMJ. 2009; 339: b2844.

41. Hunter D, Lo GH, Gale D, Grainger G, Guermazi A, Conaghan PG. The reliability of a new scoring system for knee osteoarthritis MRI and the validity of bone marrow lesion assessment: BLOKS (Boston Leeds Osteoarthritis Knee Score). Ann Rheum Dis. 2008; 67: 206-11.

42. Torres L, Dunlop DD, Peterfy C, Guermazi A, Prasad P, Hayes KW, et al. The relationship between specific tissue lesions and pain severity in persons with knee osteoarthritis. Osteoarthr Cartil. 2006; 14: 1033-40.

43. Hill CL, Gale DG, Chaisson CE, Skinner K, Kazis L, Gale ME, et al. Knee effusions, popliteal cysts, and synovial thickening: association with knee pain in osteoarthritis. J Rheumatol. 2001; 28: 1330-7.

44. Hill CL, Hunter DJ, Niu J, Clancy M, Guermazi A, Genant H, et al. Changes in synovitis are associated with changes in pain in knee osteoarthritis. Ann Rheum Dis. 2007; 66: 1599-603.

45. Zanetti M, Bruder E, Romero J, Hodler J. Bone marrow edema pattern in osteoarthritic knees: correlation between MR imaging and histologic findings. Radiology. 2000; 215: 835-40.

46. Bergman AG, Willén HK, Lindstrand AL, Pettersson HT. Osteoarthritis of the knee: correlation of subchondral MR signal abnormalities with histopathologic and radiographic features. Skeletal Radiol. 1994; 23: 445-8.

47. Dore D, Quinn S, Ding C, Winzenberg T, Zhai G, Cicuttini F, et al. Natural history and clinical significance of MRI-detected bone marrow lesions at the knee: a prospective study in community dwelling older adults. Arthritis Res Ther. 2010; 12: R223.

48. Felson DT, Niu J, Guermazi A, Roemer F, Aliabadi P, Clancy M, et al. Correlation of the development of knee pain with enlarging bone marrow lesions on magnetic resonance imaging. Arthritis Rheum. 2007; 56: 2986-92.

49. Davies-Tuck ML, Wluka AE, Wang Y, English DR, Giles GG, Cicuttini F. The natural history of bone marrow lesions in community-based adults with no clinical knee osteoarthritis. Ann Rheum Dis. 2009; 68: 904-08.

50. Kornaat PR, Bloem JL, Ceulemans RY, Riyazi N, Rosendaal FR, Nelissen RG, et al. Osteoarthritis of the knee: association between clinical features and MR imaging findings. Radiology. 2006; 239: 811-7.
51. Kornaat PR, Kloppenburg M, Sharma R, Botha-Scheepers SA, Le Graverand MP, Coene $\mathrm{LN}$, et al. Bone marrow edema-like lesions change in volume in the majority of patients with osteoarthritis; associations with clinical features. Eur Radiol. 2007; 17: 3073-8.

52. Phan CM, Link TM, Blumenkrantz G, Dunn TC, Ries MD, Steinbach LS, et al. MR imaging findings in the follow-up of patients with different stages of knee osteoarthritis and the correlation with clinical symptoms. Eur Radiol. 2006; 16: 608-18.

53. Cicuttini FM, Baker J, Hart DJ, Spector TD. Association of pain with radiological changes in different compartments and views of the knee joint. Osteoarthr Cartil. 1996; 4: 143-7.

54. Burr DB. The importance of subchondral bone in the progression of osteoarthritis. $\mathrm{J}$ Rheumatol Suppl. 2004; 70: 77-80.

55. Simkin P. Bone pain and pressure in osteoarthritic joints. Novartis Found Symp. 2004; 260: 179-86.

56. Arnoldi CC, Lemperg $\mathrm{K}$, Linderholm $\mathrm{H}$. Intraosseous hypertension and pain in the knee. J Bone Joint Surg Br. 1975; 57: 360-3.

57. Arnoldi CC, Djurhuus JC, Heerfordt J, Karle A. Intraosseous phlebography, intraosseous pressure measurements and 99mTC-polyphosphate scintigraphy in patients with various painful conditions in the hip and knee. Acta Orthop Scand. 1980; 51: 19-28.

58. Arnoldi CC. Vascular aspects of degenerative joint disorders. A synthesis. Acta Orthop Scand. 1994; 261: 1-82.

59. Roach HI, Aigner T, Soder S, Haag J, Welkerling H. Pathobiology of osteoarthritis: pathomechanisms and potential therapeutic targets. Curr Drug Targets. 2007; 8: 271-82.

60. Pesser F, Dai L, Diaz-Torne C, Gomez-Vaquero C, Paessler ME, Zheng DH, et al. The sinovytis of non inflammatory orthopedic arthropaties: a quantitative histological and immunohistochemical analysis. Ann Rheum Dis. 2008; 67: 1184-7.

61. Scanzello CR, McKeon B, Swain BH, Dicarlo E, Asomugha Eu, Kanda V, et al. Synovial inflammation in patients undergoing arthtroscopic meniscectomy: molecolar characterization and relationship to symptom. Arthritis Rheum. 2001; 63: 391-400.

62. Roemer FW, Guermazi A, Felson DT, Niu J, Nevitt MC, Crema MD, et al. Presence of MRI-detected joint effusion and synovitis at 30-month follow-up: the MOST study. Ann Rheum Dis. 2011; 70: 1804-9.

63. McDougall J. Arthritis and pain. Neurogenic origin of joint pain. Arthritis Res Ther. 2006; 8: 220.

64. Fernandez-Madrid F, Karvonen RL, Teitge RA, Miller PR, An T, Negendank WG. Synovial thickening detected by MR imaging in osteoarthritis of the knee confirmed by 
biopsy as synovitis. Magn Reson Imaging. 1995; 13: 177-83.

65. Ashraf S, Walsh DA. Angiogenesis in osteoarthritis. Curr Opin Rheumatol. 2008; 20: 573-80.

66. Latremoliere A, Woolf CJ. Central sensitization: a generator of pain hypersensitivity by central neural plasticity. J Pain. 2009; 10: 895-926.

67. Treede RD, Kenshalo DR, Gracely RH, Jones AK. The cortical representation of pain. Pain. 1999; 79: 105-11.

68. Arendt-Nielsen L, Nie H, Laursen MB, Laursen BS, Madeleine P, Simonsen OH, et al. Sensitization in patients with painful knee osteoarthritis. Pain. 2010; 149: 573-81.

69. Fishbain D. Evidence-based data on pain relief with antidepressants. Ann Med. 2000; 32: 305-16.

70. Phillips K, Clauw DJ. Central pain mechanism in the rehematic diseases. Arthritis Rheum. 2013; 65: 291-302.

71. Felson D. The sources of pain in knee osteoarthritis. Curr Opin Rheumatol. 2005; 17: 624-8.

72. Hunter DJ, McDougall JJ, Keefe FJ. The symptoms of osteoarthritis and the genesis of pain. Rheum Dis Clin North Am. 2008; 34: 623-43.

73. Kean WF, Kean R, Buchanan WW. Osteoarthritis: symptoms, signs and source of pain. Inflammopharmacology. 2004; 12: 3-31.

74. Jordan J, Luta G, Renner J, Dragomir A, Hochberg M, Fryer J. Knee pain and knee osteoarthritis severity in self-reported taskspecific disability: The Johnston County Osteoarthritis Project. J Rheumatol. 1997; 24: 1344-9.

75. Perrot S, Poiraudeau S, Kabir-Ahmadi M, Rannou F. Correlates of pain intensity in men and women with hip and knee osteoarthritis. Results of a national survey: The French ARTHRIX study. Clin J Pain. 2009; 25: 767-72.

76. Veenhof C, Huisman PA, Barten JA, Takken T, Pisters MF. Factors associated with physical activity in patients with osteoarthritis of the hip or knee: a systematic review. Osteoarthritis Cartilage. 2012; 20: 6-12.

77. Salaffi F, Leardini G, Canesi B, Mannoni A, Fioravanti A, Caporali R, et al. Reliability and validity of the Western Ontario and McMaster Universities (WOMAC) Osteoarthritis Index in Italian patients with osteoarthritis of the knee. Osteoarthritis Cartilage. 2003; 11: 551-60.

78. Summers MN, Haley WE, Reveille JO, Alarcon GS. Radiographic assessment and psychological variables as predictors of pain and functional impairment in osteoarthritis of the knee or hip. Arthritis Rheum. 1988; 31: 204-9.
79. Hochberg MC, Lawrence RC, Everett DF, Cornoni-Huntley J. Epidemiological association of pain in osteoarthritis of the knee. Semin Arthritis Rheum. 1989; 18: 4-9.

80. Lethbridge-Cejku M, Scott WW Jr, Reichle R, Ettinger WH, Zonderman A, Costa P, et al. Association of radiographic features of osteoarthritis of the knee with knee pain: data from the Baltimore Longitudinal Study of Aging. Arthritis Care Res. 1995; 8: 182-8.

81. Creamer P, Lethbridge-Cejku M, Hochberg MC. Determinants of pain severity in knee osteoarthritis: effect of demographic and psychosocial variables using 3 pain measures. J Rheumatol. 1999; 26: 1785-92.

82. Cimmino MA, Salaffi F, Olivieri I, Trotta F, Frizziero L, Sarzi-Puttini P, et al. Pain patterns in Italian patients with osteoarthritis: preliminary results of the MI.D.A. Study (Misurazione del Dolore nell'Artrosi). Reumatismo. 2004; 56: 253-61.

83. Salaffi F, Piva S, Barreca C, Cacace E, Ciancio G, Leardini G; on behalf of Gonarthrosis and Quality of Life (GOQUOLA) Study Group. Validation of an Italian version of the arthritis impact measurement scales 2 (ITALIAN-AIMS2) for patients with osteoarthritis of the knee. Rheumatology. 2000; 39: 720-6.

84. Keefe FJ, Affleck G, France CR, Emery CF, Waters S, Caldwell DS, et al. Gender differences in pain, coping, and mood in individuals having osteoarthritic knee pain: a withinday analysis. Pain. 2004; 110: 571-7.

85. Miranda H, Viikari-Juntura E, Martikainen R, Riihimäki H. A prospective study on knee pain and its risk factors. Osteoarthritis Cartilage. 2002; 10: 623-30.

86. Keefe FJ, Lefebvre JC, Egert JR, Affleck G, Sullivan MJ, Caldwell DS. The relationship of gender to pain, pain behavior, and disability in osteoarthritis patients: the role of catastrophizing. Pain. 2000; 87: 325-34.

87. Allen KD, Coffman CJ, Golightly YM, Stechuchak KM, Keefe FJ. Daily pain variations among patients with hand, hip, and knee osteoarthritis. Osteoarthritis Cartilage. 2009; 17: 1275-82.

88. Cimmino M, Sarzi-Puttini P, Scarpa R, Caporali R, Parazzini F, Zaninelli A, et al. Clinical presentation of osteoarthritis in general practice: determinants of pain in Italian patients in the AMICA Study. Semin Arthritis Rheum. 2005; 35: 17-23.

89. Franchignoni F, Salaffi F, Giordano A, Carotti M, Ciapetti A, Ottonello M. Rasch analysis of the 22 knee injury and osteoarthritis outcome score-physical function items in Italian patients with knee osteoarthritis. Arch Phys Med Rehabil. 2013; 94: 480-7.

90. Franchignoni F, Salaffi F, Giordano A, Ciapetti A, Carotti M, Ottonello M. Psychomet- 
ric properties of self-administered Lequesne Algofunctional Indexes in patients with hip and knee osteoarthritis: an evaluation using classical test theory and Rasch analysis. Clin Rheumatol. 2012; 31: 113-21.

91. Muthuri SG, Hui M, Doherty M, Zhang W. What if we prevent obesity? Risk reduction in knee osteoarthritis estimated through a meta-analysis of observational studies. Arthritis Care Res. 2011; 63: 982-99.

92. Salaffi F, Cavalieri F, Nolli M, Ferraccioli GF. Analysis of disability in knee osteoarthritis. Relationship with age and psychological variables but not with radiographic score. J Rheumatol. 1991; 18: 1581-6.

93. Davis MA, Ettinger VH, Neuhaus JM, Barclay JD, Segal MR. Correlates of knee pain among United States adults with and without radiographic knee osteoarthritis. J Rheumatol. 1992; 19: 1943-9.

94. Holla JF, van der Leeden M, Knol DL, Roorda LD, van der Esch M, Voorneman $\mathrm{RE}$, et al. The association of body-mass index and depressed mood with knee pain and activity limitations in knee osteoarthritis: results from the Amsterdam osteoarthritis cohort. BMC Musculoskelet Disord. 2013; 14: 296.

95. Paradowski PT, Englund M, Lohmander LS, Roos EM. The effect of patient characteristics on variability in pain and function over two years in early knee osteoarthritis. Health Qual Life Outcomes. 2005; 3: 59.

96. Oliveria SA, Felson DT, Cirillo PA, Reed JI, Walker AM. Body weight, body mass index, and incident symptomatic osteoarthritis of the hand, hip, and knee. Epidemiology. 1999; 10: 161-6.

97. Addimanda O, Mancarella L, Dolzani P, Ramonda R, Fioravanti A, Brusi V, et al. Clinical associations in patients with hand osteoarthritis. Scand J Rheumatol. 2012; 41: 310-3.

98. Massengale M, Lu B, Pan JJ, Katz JN, Solomon DH. Adipokine hormones and hand osteoarthritis: radiographic severity and pain. PLoS One. 2012; 7: e47860.

99. Hopman-Rock M, Odding E, Hofman A, Kraaimaat FW, Bijlsma JWJ. Differences in health status of older adults with pain in the hip or knee only and with additional mobility restricting conditions. J Rheumatol. 1997; 24: 2416-23.

100. Juhakoski R, Tenhonen S, Anttonen T, Kauppinen T, Arokoski JP. Factors affecting selfreported pain and physical function in patients with hip osteoarthritis. Arch Phys Med Rehabil. 2008; 89: 1066-73.

101. Verbrugge LM, Cates DM, Ike RW. Risk factors for disability among U.S. adults with arthritis. J Clin Epidemiol. 1991; 44: 167-82.

102. Verbrugge LM, Lepkowski JM, Konkol LL.
Levels of disability among U.S. adults with arthritis. J Gerontol 1991; 46: S71-83.

103. Guralnik JM, LaCroix AZ, Everett DF, Kovar MG. Aging in the Eighties: the prevalence of comorbidity and its association with disability advance data from vital and health sciences, No. 170. DHHS Publication No. PHS 89-1250. Hyattsville: National Center for Health Statistics. 1989.

104. Badley EM, Rasooly I, Webster GK. Relative importance of musculoskeletal disorders as a cause of chronic health problems, disability, and health care utilization: findings from the 1990 Ontario Health Survey. J Rheumatol. 1994; 21: 505-14.

105. Hochberg MC, Kasper J, Williamson J, Skinner A, Fried LP. The contribution of osteoarthritis to disability: preliminary data from the women's health and aging study. J Rheumatol. 1995; 22: 16-8.

106. Callahan LF, Smith WJ, Pincus T. Selfreport questionnaires in five rheumatic diseases. Arthritis Care Res. 1989; 2: 122-31.

107. Birrell F, Croft P, Cooper C, et al. Health impact of pain in the hip region with and without radiographic evidence of osteoarthritis: a study of new attenders to primary care. Ann Rheum Dis 2000; 59: 857-63.

108. Stewart AL, Greenfield S, Hays RD, Wells K, Rogers WH, Berry SD, et al. Functional status and well-being of patients with chronic conditions. Results from the Medical Outcome Study. JAMA. 1989; 262: 907-13.

109. O'Reilly SC, Muir KR, Doherty M. Screening for pain in knee osteoarthritis: which question? Ann Rheum Dis. 1996; 55: 931-3.

110. Felson DT, Naimark A, Anderson J, Kazis L, Castelli W, Meenan RF. The prevalence of knee osteoarthritis in the elderly. The Framingham Osteoarthritis Study. Arthritis Rheum. 1987; 30: 914-8.

111. Kane RL, Bershadsky B, Lin WC, Rockwood T, Wood K. Efforts to standardize the reporting of pain. J Clin Epidemiol. 2002; 55: 105-10.

112. Orbell S, Johnston M, Rowley D, Espley A, Davey P. Cognitive representations of illness and functional and affective adjustment following surgery for osteoarthritis. Soc Sci Med. 1998; 47: 93-102.

113. Keefe FJ, Smith SJ, Buffington AL, Gibson J, Studts JL, Caldwell DS. Recent advances and future directions in the biopsychosocial assessment and treatment of arthritis. J Consult Clin Psychol. 2002; 70: 640-55.

114. Brenes GA, Rapp SR, Rejeski WJ. Do optimism and pessimism predict physical functioning? J Behav Med. 2002; 25: 219-31.

115. Van Baar ME, Dekker J, Lemmers JA. Pain and disability in patients with osteoarthritis of hip or knee. J Rheumatol. 1998; 25: 125-33.

116. Tak SH, Laffrey SC. Life satisfaction and its 
correlates in older women with osteoarthritis. Orthop Nurs. 2003; 22: 182-9.

117. Gignac MA, Davis AM, Hawker G. "What do you expect? You're just getting older": a comparison of perceived osteoarthritisrelated and aging - related health experience in middle- and older-age adults. Arthritis Rheum. 2006; 55: 905-12.

118. Cook C, Pietrobon R, Hegedus E. Osteoarthritis and the impact on quality of life health indicators. Rheumatol Int. 2007; 27: 315-21.

119. Davis MA, Ettinger WH, Neuhaus JM, Mallon KP. Knee osteoarthritis and physical functioning: evidence from the NHANES I epidemiologic follow-up study. J Rheumatol. 1991; 18: 591-8.

120. Dekker J, Boot B, van der Woude L, Bijlsma JWJ. Pain and disability in osteoarthritis: a review of biobehavioral mechanisms. J Behav Med. 1992; 15: 189-214. 